\title{
Symptoms of post-traumatic stress among victims of school bullying
}

\author{
Luky Kurniawan $^{1}$, Natri Sutanti ${ }^{2}$, Zalik Nuryana ${ }^{3,4}$ \\ ${ }^{1}$ Department of Guidance and Counseling, Universitas Mercu Buana Yogyakarta, Yogyakarta, Indonesia \\ ${ }^{2}$ School of Education, Faculty of Social Sciences, University of Nottingham, Nottingham, United Kingdom \\ ${ }^{3}$ Department of Islamic Education, Faculty of Islamic Studies, Universitas Ahmad Dahlan, Yogyakarta, Indonesia \\ ${ }^{4}$ School of Education and Science, Nanjing Normal University, Nanjing, China
}

\begin{tabular}{l} 
Article Info \\
\hline Article history: \\
Received Apr 23, 2021 \\
Revised Nov 9, 2021 \\
Accepted Nov 21, 2021 \\
\hline
\end{tabular}

\section{Keywords:}

Anxious

Emotion

School bullying

Silent

Student's stress

Symptoms of post-traumatic

\begin{abstract}
School bullying is a critical issue among students that can promote some mental health issues. Some studies had found that severe or frequent bullying can lead to the development of post-traumatic stress symptoms such as avoidance behaviours and anxious feelings. However, school bullying is difficult to observe due to the complexity factors such as cultural background, peer pressure and academic problems. The study aimed to investigate the symptoms of post-traumatic stress among victims of school bullying. The study employed a descriptive qualitative research design. The data was collected by using a questionnaire to 42 students from two vocational high schools in Yogyakarta who had severe or frequent experience of school bullying. The results revealed that 40 per cent of participants showed one or more symptoms of post-traumatic stress such as feeling persistently avoiding to the perpetrators and feeling extremely anxious about the potential being bullied again. Meanwhile, 60 per cent participants experienced some other difficult emotions such as anger, revenge, disappointment, and sadness. The results also showed that the two biggest changes experienced by students after bullying were becoming more silent and being frequently anxious compared to before being bullied. The study suggests the need for further research to investigate the level of posttraumatic stress experienced by the students and the urge for anti-bullying curriculum in both schools to prevent the serious consequences of bullying.
\end{abstract}

This is an open access article under the CC BY-SA license.

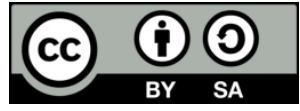

\section{Corresponding Author:}

Natri Sutanti

School of Education, Faculty of Social Sciences, University of Nottingham

NG7 2RD, Nottingham, United Kingdom

Email: ttxns45@nottingham.ac.uk

\section{INTRODUCTION}

Bullying at school has been identified as one of the predominant traumatic stressors that can cause physical and mental health problems to victims, such as anxiety, depression, avoidance symptoms and suicidal thoughts [1]-[4]. Based on the result of the Global School-based Student Health Survey (GSHS) in Indonesia by the World Health Organisation (WHO), there has been an uptick in anxiety and risk behaviours, such as aggressive behaviour, suicide attempts and drug abuse [5]. 49.7 per cent of GHSH student participants reported being bullied on one or more days in the last 30 days and 8.2 per cent reported having encountered physical abuse. Since bullying has been a global problem, a comparable figure has also been identified in Norway and the United Kingdom. The prevalence rate of school bullying in Norway was about 31 per cent [6], while in the United Kingdom, a study undertaken by an anti-bullying group showed that 22 
per cent of student participants had been bullied in the past 12 months [7]. These numbers are projected to rise constantly due to systematic cyberbullying, which is another form of bullying.

Even when school bullying can be triggered by more than one factor [8]-[10] and can be a type of bullying that arises inside the family or in a broader social setting beyond the school [7], school as an educational institution is frequently assumed to be a sole entity responsible for resolving the problem. However, overseeing the school to incarnate responsibility is a big obstacle due to the difficulties in creating a definitive list of bullying behaviours. Olweus [11] describe bullying as frequent exposure to people or groups, including teasing, name-calling, mocking, intimidation, harassment, taunting, beatings, social isolation or gossip that can lead to physical harm, death, disability, and some psychological distress. Furthermore, Einarsen [12] considers badgering and being made the laughing stock of the classroom as types of bullying behaviours. Despite the serious impacts and complex ways of bullying, Dokgöz et al. [13] concluded that school bullying will continue to attract attention from researchers, educators and society. Research done by Smith et al. [14] reported that school-based victimization raises the risk of being bullied in adult life. This shows the continuous detrimental influence that could linger with the victims of bullying throughout their life. Nansel et al. [15] have found that bullying could be harmful to the wellbeing of the victim. Nielsen et al. [1] further report that bullying is associated with post-traumatic stress (PTS).

PTS is characterized as an anxiety disorder as a result of certain types of encounter with death, injury and life-threatening incidents, such as major disasters, injuries, criminal victimization, sexual abuse/assault, war encounters and illness [16]. Although bullying is not a single traumatic exposure, Matthiesen and Einarsen [17] assert that the distress of multiple bullying equalises to stress caused by traumatic events. Research has demonstrated that verbal abuse has a greater effect on the emerging symptoms of PTS than physical bullying [18]. However, identifying bullying in school and understanding the impacts on the student's wellbeing are challenging due to the lack of awareness in this regard. People usually believe that harassment is normal among teens, which includes only mild bullying and harassment [19]. It leads to severe depression and trauma that can affect student success at school. Studies also found that bullying is highly associated with symptoms of PTS [1], [2], [9], [20]-[24]. In their research, Nielsen et al. [1] found that $57 \%$ of individuals who were bullied had a psychological threshold in the post-traumatic stress disorder test. Ossa et al. [2] have found that $50 \%$ of the population of extreme school bullying in their sample had hit the tipping point for suspected PTS. Both reports have confirmed some of the previous studies of school bullying in the early 2000s by Mynard et al. [20] and McKenny et al. [21] which revealed about 37\% of victims of bullying reporting symptoms of PTS, such as intrusive memories and avoidance behaviour. These findings showed that school bullying has a high propensity to promote some symptoms of PTS in victims. Many studies on school bullying that investigate PTS have primarily used a quantitative approach and only a small number used a qualitative method, although both approaches are equally relevant for research on bullying [25].

Therefore, the current study aimed to investigate the symptoms of PTS among victims of school bullying. The study used a descriptive qualitative approach to analyze the topic that it could capture the uniqueness of the victims' experience of school bullying. The exploration in the study focused on understanding an individual's experience of being bullied and identifying whether the experience promoted some symptoms of PTS such as avoidance tendency, intrusion, negative feeling (anxious or guilty), and sleeping problems [26], [27]. The research was conducted in two vocational high schools in Yogyakarta, Indonesia. The level of bullying for children aged 13-17 years in Yogyakarta reached 21\% in 2019 and was recorded as the area with the highest bullying rate in 2008 [28], [29]. Based on research by the Program for International Students Assessment (PISA) in 2018, it was recorded that $41 \%$ of Indonesian students had experienced bullying a few times, a month and became the 5th highest country out of 78 countries in the terms of bullying [30].

\section{RESEARCH METHOD}

\subsection{Research design}

The study was used a descriptive qualitative approach that aims to describe a phenomenon and its characteristics [31]. In this study, the researchers tried to identify the symptoms of PTS among the student participants. The study was guided by a research question that was how school bullying impacts on student participants' psychological conditions related to the symptoms of PTS. The study invited forty-two students, who identified themselves as a victim of school bullying. Students who agreed to participate in the study asked to complete a questionnaire with open questions that was designed to be completed in about 30 minutes throughout an online survey platform. 


\subsection{Population and sample}

The study took place in two vocational high schools in Yogyakarta, Indonesia. The selection of vocational high schools was motivated by the compatibility of the characteristics of vocational school students who were identical with brawls, a school bullying and the very heterogeneous background of students towards the direction of the study [32]. Therefore, it is predicted that vocational high school students have more vulnerability to bullying and PTS symptoms. The research used a purposive sampling technique to choose samples based on the purpose of the research. Forty-two student participants were identified as victims of school bullying. Twenty-nine students came from a school, and the remaining thirteen were from B school. The participants consisted of 22 male students and 20 female students. The 22 students were in Grade 10, while 7 were in Grade 11 and the rest were in Grade 12. The age group of participants ranged from 15 years to 18 years. All participants had agreed to take part in the study and had given their consent.

\subsection{Instruments}

This data was collected at the end of 2020 when students were undergoing distance learning due to the COVID-19 pandemic. Although the research was undertaken when students did not interact at school due to distance learning, the obtained data were intended to remain significant because the present study aimed to determine the effects of post-traumatic stress-related bullying. The questionnaire was chosen as the most appropriate tool for the existing situation. The questionnaire consists of 8 different questions. This questionnaire was prepared following the framework of research by Mikkelsen and Einarsen [33] that was the prevalence and intensity of post-traumatic stress disorder (PTSD) analogue symptomatology among victims of bullying. The questions given are in the form of open-ended questions and the place to fill out the questionnaire is conditioned so that participants can freely share their stories and feelings without limiting the participants' responses. Researchers also collaborated with teachers in each school to be able to assist students virtually in answering the questionnaire. This is done so that the data obtained remains valid and sufficient for qualitative analysis. The first five questions identified the content of bullying, while the two investigated the impact of bullying related to the symptoms of PTS and one question captured the changes after bullying. The questionnaire was designed to be completed in about 30 minutes throughout an online survey platform.

There are some limitations to this study regarding the number of participants and the depth of information from the questionnaire. Although a qualitative study does not require a big number of participants, having more participants is actually beneficial to comprehend the data, for instance, a study by Espelage and Asidao [34] with 89 participants that can show more comprehensive overviews about the phenomena of school bullying in a Mid-Western State. However, due to the difficult circumstances in the aftermath of the COVID-19 pandemic and the numerous technological challenges faced by participants, such as inadequate internet networks, this study has not been prepared to carry out more exploration through focus group discussions. Therefore, further study is recommended to recruit more participants and do focus group discussions to thoroughly understand and examine comorbidities of the school bullying phenomena related to PTS.

\subsection{Analysis}

As the study employed a descriptive qualitative approach, the data were analyzed by using inductive thematic analysis to find classifications and patterns of present themes among the participants before the data were interpreted [29], [35]. Initially, the participants' responses were read and coded by considering some similarities within the data to identify themes. The themes were reviewed and reread to decide the final draft. The themes found from the results of the data processing of the open-ended questionnaire were divided into two, namely bullying and PTS symptoms. In the bullying theme, several sub-themes were found including form of bullying, specific types of bullying, reasons of bullying, frequency of bullying, when the bullying happened and place of bullying. Meanwhile, on the PTS symptom theme, there are sub-topics when the most serious bullying ever encountered by participants, impact of bullying related to PTS and changes after bullying related to PTS. To obtain further comparison and evaluation, the data were also analyzed quantitatively using frequencies and percentages [30]. Meanwhile, some interesting findings were discussed qualitatively.

\subsection{Ethical clearance}

The study had obtained ethical approval from Universitas Mercu Buana Yogyakarta (224/C.02/H1/XIII/2020). The 42 students who agreed to participate and given written informed consent were enrolled. 


\section{RESULTS AND DISCUSSION}

\subsection{Bullying profile}

The findings reveal that three forms of bullying have been reported, namely verbal, non-verbal and cyber-bullying. According to Table 1, there are $69 \%$ of students admitted to verbal bullying and 5\% encountered cyber-bullying. Meanwhile, the remaining $27 \%$ encounters more than one form of bullying. Taunting and labelling or name-calling is the most common types of bullying, accounting for $74 \%$ of the responses. Whereas, ignoring and hitting are identified at $9 \%$ each and the remaining were social media mockery, teasing and intimidation at less than 5\% each. The findings also reveal that the most common causes for the bullying are a physical appearance reported at $38 \%$ and follow by the uniqueness of the parent's name at $29 \%$. While the remaining percentage represents the reasons for the family economic status, lisp and for making mistakes, as seen in seen Table 1.

Table 1. Bullying profile

\begin{tabular}{lc}
\hline \multicolumn{1}{c}{ Aspects } & Percentage \\
\hline Form of bullying & $69 \%$ \\
Verbal & $5 \%$ \\
Cyber-bullying & $27 \%$ \\
More than one form of bullying (verbal, non-verbal or cyber-bullying) & \\
Specific types of bullying & $2 \%$ \\
Intimidation & $2 \%$ \\
Making fun of someone/teasing & $4 \%$ \\
Being sarcastic in social media/mocking & $9 \%$ \\
Hitting & $9 \%$ \\
Ignoring & $13 \%$ \\
Name calling/labelling & $61 \%$ \\
Taunting & \\
Reasons of bullying & $3 \%$ \\
Make a mistake & $6 \%$ \\
Lisp & $12 \%$ \\
Family status/economic factor & $18 \%$ \\
Parents' name (unique) & $24 \%$ \\
Physical appearance & $38 \%$ \\
Not specified &
\end{tabular}

One of the important aspects in the bullying profile related to PTS is the frequency of bullying that occurs. According to Matthiesen and Einarsen [17] multiple bullying is equivalent to stress caused by a traumatic event. In other words, bullying with high or repeated frequency has a great potential to cause PTS. In this study, it turned out that 27 students reported experiencing bullying often, i.e., twice a month to every day and 15 students experiencing bullying less frequently, which is about once every two months or so, further details can be seen in Figure 1. This shows that there is a great potential for victims of bullying to experience trauma. Furthermore, Walsht and Clarke [18] explained that verbal bullying has a greater effect on PTS symptoms that arise than physical bullying, where in this study the most common type of bullying was verbal bullying.

Number of students based on the frequency of bullying

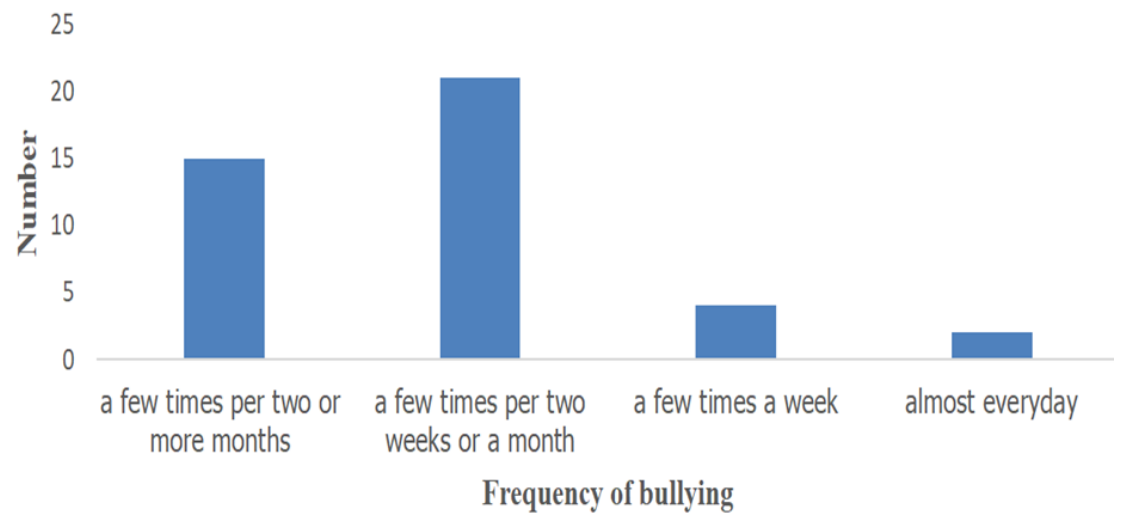

Figure 1. Number of students based on the frequency of bullying

Int J Public Health Sci, Vol. 11, No. 1, March 2022: 263-273 
In terms of when bullying occurring, $72 \%$ of student participants report being bullied in class when there are free hours or during certain subjects, while the rest declare being bullied in the school canteen, in a quiet place at school, or anywhere when they meet $8 \%$ of them confess to being bullied outside of school on their way home. Whereas, $80 \%$ of students report that they experience bullying the most when school hours are empty or during lunch breaks. The rest report that bullying occurs during certain class hours, whenever they meet, when they make mistakes and when they come home from school.

\subsection{Impacts related to symptoms of post-traumatic stress}

The findings shown in this section are intended to determine whether the bullying has contributed to the development of symptoms of post-traumatic stress. Therefore, the questions raise to reveal when the most serious bullying is happens and how it has an impact on participants' feelings. Figure 2 reveals that the largest proportion of the most severe bullying is experienced by participants occurring in junior high schools that reaches $41 \%$. Meanwhile, the overall number of cases reaches $53 \%$ in junior high school. This is followed by the frequency of elementary schools with a sum of $31 \%$ and the rate in secondary schools is the lowest, $16 \%$. Some participants had reported more than one point in time when they encounter severe bullying, for example, the prevalence in primary and junior high schools reach $10 \%$. The remaining $12 \%$ of participants did not mention a specific time when the heaviest bullying was experienced. High reports of the most serious bullying in junior high school are possible because the number of respondents in 10 grades is more than half of the overall participants. This means they have just graduated from junior high school.

The finding shows a pattern that bullying occurs more in early adolescence at junior high school age and the number seems to decrease when entering senior high school. This is in accordance with the results of a survey from the National Center for Education Statistics in 2017 which showed that the percentage of bullying in junior high school students reached $24.6 \%$ or in other words it was higher than high school which was only $16.3 \%$ [36]. Referring to the theory of child and adolescent development, it can be seen that adolescence is indeed a transitional period where the level of emotional stability of children has not yet reached maturity and is followed by hormonal changes that often trigger curiosity and excessive emotions [37]. Therefore, it is reasonable that the difference in the intensity of bullying between junior high school and high school students is related to the level of emotional maturity. The more mature a person is, they tend to be more able to control their behaviour, so that bullying in adulthood is usually lower than in adolescence.

According to Figure 1, the analysis of the questionnaire also found that victims of bullying had a range of effects varying from negative to positive. The surprising finding is that $1 \%$ of respondents admit that they became more confident and motivated to do better after being bullied. The highest percentages of the impact of bullying were feelings of anxiety and avoidance at $23 \%$ and $17 \%$, respectively. Other emotions that result from bullying include being resentful, disappointed, feeling worthless, not bothered, quiet, silent, and sad. Meanwhile, feelings that contribute to violence are vengeful and angry, $4 \%$ and $9 \%$. It is therefore not surprising for victims of bullying to become bullies because of their resentments and frustration of bullying. However, emotions that are commonly felt tend to be dominated by feelings of distress, avoidance, anxiety, sadness, and dissatisfaction. The findings shown in Figure 2 reveal that the two emotions with the greatest proportion, namely feelings of anxiety and avoidance that are also symptoms of PTS.

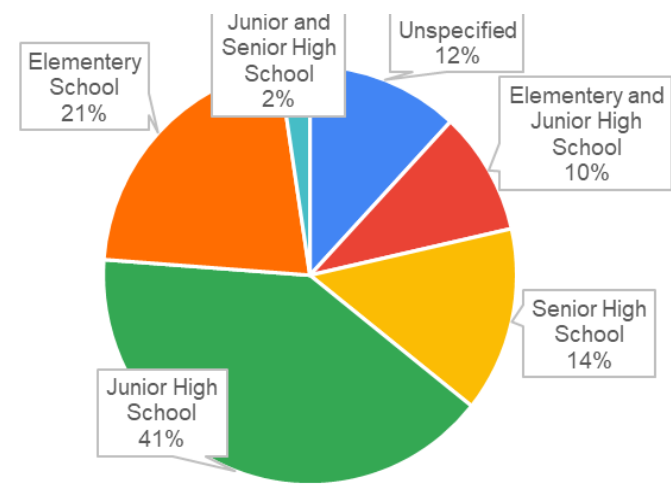

Figure 2. Responses to when the most serious bullying ever encountered by participants

However, the assessment of PTS cannot be verified only by the existence of these two emotions, as according to the Children's Updated Effect of Case Scales [26] and the Post-Traumatic Symptom Scale [27], the indications of PTS entail avoidance, anxiety/intrusive thoughts, sleeping problems, nightmares, arousal, 
self-isolation, muscular tension and fear of places or situations resembling to the traumatic event. It takes a thorough evaluation by a clinical psychologist or psychiatrist to be able to conclude that the victim of the bullying has PTS. From these findings, however, it can be found that victims of bullying appear to have feelings that suggest PTS, such as avoiding actions and extreme anxiety.

Based on the findings, it can also be inferred that $40 \%$ of the respondents have one or more signs of post-traumatic stress, such as persistently avoiding the perpetrators and becoming highly anxious about the risk to be bullied again. The $60 \%$ of the participants reported certain other difficult feelings, such as anger, vengeance, dissatisfaction, and despair as displayed in Figure 3.

\section{Impact of school bullying}

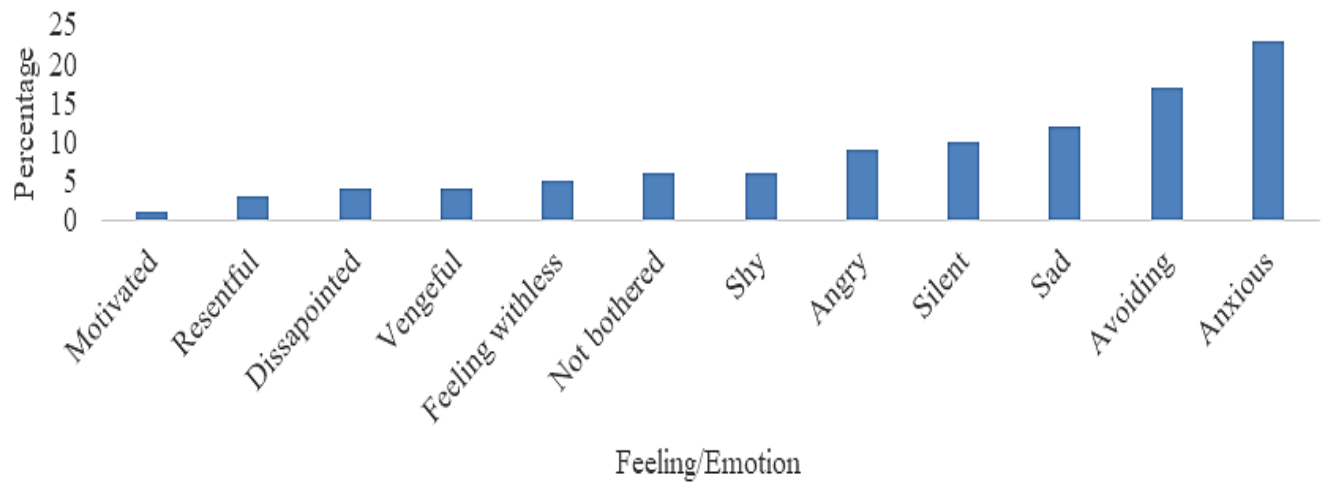

Figure 3. Impact of school bullying

\subsection{Changes among victims of school bullying}

In addition to the symptoms of PTS, the results of the students' responses to the questionnaire further reflected the changes they encountered after being bullied, whether they perceived it immediately or continued a long time. Figure 4 shows that the two most noticeable changes that arise in victims of bullying are becoming a reserved person and that they are more anxious than before, $27 \%$ each. The results in Figure 3 confirm the observations in the previous section that there are several PTS symptoms as indicated by the changes that emerge, i.e., being more anxious than before and preferring to avoid bullying with a ratio of $27 \%$ and $14 \%$, respectively. Specific findings have been seen by the inclusion of $7 \%$ of respondents who acknowledged that they were more optimistic after bullied and $6 \%$ who genuinely wished to be even better. In general, the trend in these results is not that different from the impacts of bullying, but this section also confirms and reinforces those victims of bullying appear to suffer one or more PTS symptoms.

\section{The changes after bullying}

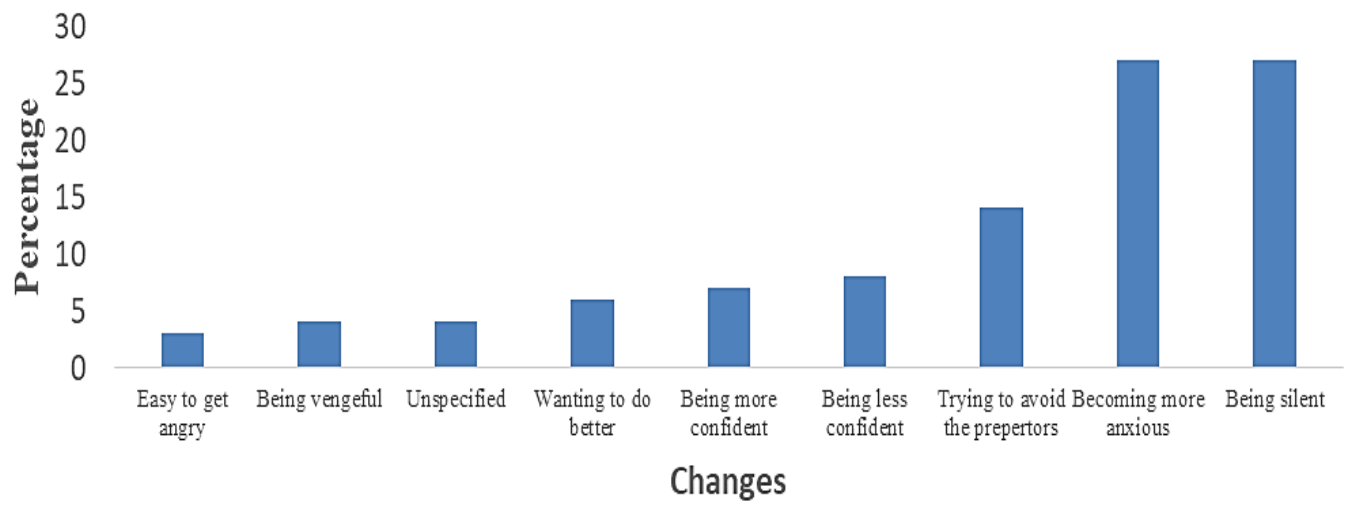

Figure 4. The changes after bullying 
Smith et al. [14] state that bullying among children and adults is interrelated phenomena. In their study, they discovered that victimization from school bullying can increase the risk of being bullied in adult life. This is in line with a study by Ttofi et al. [38] that found a person who bullies others in school tend to bully as an adult. It means that both victims and perpetrators of bullying have an intergenerational tendency that can lead to severe psychological distress for the victims. Therefore, it is important to investigate the impacts of school bullying towards victims to be able to minimalize the physical and psychological harms including the emergence of symptoms of post-traumatic symptoms. Based on the results, student participants show various psychological distresses and avoidance symptoms as impacts of bullying. All participants reported that they experienced some difficult feelings such as annoyed, sad, anxious, disappointed, and angry and at the same time, they were also powerless to express their feelings. Most of them preferred to suppress their emotions and try to avoid any communication and interaction with the perpetrators. The selected responses of avoidance tendency and difficult feelings from the questionnaire can be found as follows.

"I started worrying and was scared to face the bullies. I chose to shut myself down and to avoid them. I still felt undue anxiety, and, at the same time, I held a grudge against them. For a second, I felt I was useless." (Participant-IA6)

"I feel reluctant to meet people who are cheating on me, and I better avoid them. I was going to retaliate, but I did not dare because they were a bunch. Often, I pretend that I do not see them as I step by them." (Participant-AV6)

"I am upset about my embarrassment. But they hate me even more if I fight them, so I choose silence." (Participant-DY2)

From the selected response, it can be observed that, in general, the respondents encountered more than one difficult emotion. Besides, the emotions as seen from the three respondents are mostly related to avoidance tendency and anxiety. Respondents also hesitate to revenge even though they have resentment and anger, and they prefer not to risk fighting since most of the bullies are in groups. Some feelings mentioned meet some criteria of PTS according to Children's Revised Impact of Event Scales [26] and Post-traumatic Symptoms Scale [27] that state the symptoms of post-traumatic stress including avoidance, intrusive thoughts, sleeping problems, nightmares, arousal, tendency to do self-isolation, muscular tension and fear of places or situations resembling the traumatic event. Moreover, based on the actual responses in Figure 2 and 3 , it can be seen that $40 \%$ of participants experienced some symptoms of PTS, while $60 \%$ of them reported some other difficult feelings such as anger, sadness and disappointment [39], [40]. Referring to the Participant-IA6, bullying has made him feel annoyed and upset which then led to the anxious feeling of how if he will be bullied again. Therefore, the participant then preferred to disconnect and shut him down to avoid the bullying. From Participant-AV6 response, it seems that although the victim has the power to stand up for herself when encountering the perpetrators, it is still impossible to fight back as the perpetrators are always in a group. Eventually, all victims established the avoidance behaviours due to powerlessness and vulnerability. Pimentel et al. [41] stated that some bullying victims are highly vulnerable to develop PTS symptoms. This statement is also supported by the studies from Liu et al. [42] and Idsoe et al. [23] that stated exposure to bullying is a positive predictor for PTS symptoms among students. Further evidence of PTS symptoms in the study are described explicitly by the following two responses.

"I felt anxious and was terrified to meet the bullies. In the end, I just decided to stay quiet to avoid them, because I felt excessive fear and fury, but I will not dare to fight back. I feel worthless, too, and my life is pointless. Not only am I terrified of bullies, but I am also still scared of having to meet new people. And without understanding the reason, I cry all the time, and all I feel is sad." (Participant-RV2)

"Because of my appearance, I was regularly humiliated in elementary and middle school. I did not even care about it now, but because of the constant feeling that I began to feel wounded. I sometimes felt I was going to die because life was not easy. The incidents I have witnessed didn't just end at school as I've even been bullied outside. Until I found it hard to sleep and cried until I got a headache. I was even embarrassed and scolded in front of strangers. Until now, all that traumatized me, and even in this high school, I became a quiet person because I was terrified." (Participant-DF2)

Both responses reinforce that there is likelihood for victims of bullying to experience PTS. Moreover, Participant-DF2's statement admitted that he had experienced trauma after being repeatedly blotted both at school and outside of school. This main finding that school bullying was indicated to cause some symptoms of post-traumatic stress among victims of bullying is in line with some previous studies [1], 
[2], [9], [20]-[23], [33], [43], [44]. Avoidance behaviours, anxious feeling and some others difficult feeling observed in this study were also reported in the studies by Arnout et al. [45] and by Yasmin and Nurcahyani [46]. Both studies stated that some symptoms of post-traumatic stress observed in their study included avoidance, negative emotions (anxious, guilty, anger and upset), emotional numbness and social withdrawal that were similar with the finding in this study. Moreover, according to Terr [47], an individual who has repeated bullied, experiences a similar situation of helplessness as a victim of trauma. In the context of bullying, helplessness could be understood as being powerless due to the domination of the perpetrators; therefore, the victims are unable to fight back and establish some avoidance behaviours. It is reasonable when Veenstra et al. [48] states that bullying could be considered as a repeated trauma as the impact of bullying equally detrimental to experiencing trauma.

Other results of this research further indicate that verbal abuse is the highest proportion compared to other forms of bullying. The $69 \%$ of students admitted to verbal bullying, and at the same time 40 per cent of participants showed one or more symptoms of PTS. It can be predicted that there is a correlation between verbal bullying and PTS. The prediction from this study has been proven by a study from Walsht and Clarke [18] that found verbal abuse has a greater effect on the emerging symptoms of PTS than physical bullying. In the study, the most common types of verbal bullying are taunting and labelling or name-calling accounting for $74 \%$ of the responses. Despite indicating the various forms of bullying, the results also show the reasons why the participants were bullied by their peer. The most common causes for the bullying are a physical appearance reported at $38 \%$ and follow by the uniqueness of the parent's name at $29 \%$. The findings reaffirm the previous research discovering that the common reason of students being bullied is because they are different compared to the general population such as in terms of physical appearance, behaviour or way of speaking [49]-[52]. The victims are always perceived as having no capacity to fit into the group. Therefore, bullying sometimes is used to exclude individuals who are significantly different from the peer group to maintain conformity and group reputation [53].

Understanding the reasons for school bullying could not be separated from recognising the cultural background and social hierarchy of the victims and perpetrators [29]. Similar to other Asian countries, Indonesian culture tends to uphold the value of collectivism within diverse ethnic groups [54]-[56]. On the one hand, living in a diverse society benefits people to establish their sense of respect and tolerance towards others. On the other hand, having collectivistic value while living in a diverse society is quite challenging as collectivists tend to create a group that consists of people with similar appearance, background, or thoughts. Eventually, it will form a social hierarchy that divides people into some various social group levels. When people could not fit into the popular group, they will try to create another group which is less popular but more accepting. Cadigan [57] and Philips [58] states that the level of popularity among students segregates them into three different groups: low, middle and high-status students. Low-status students especially socalled 'odd' and 'loners' often become the typical targets of bullying.

Furthermore, referring to Rogers' theory of necessary and sufficient conditions [59], [60] it can be understood that the root of the school bullying phenomena is the lack of acceptance or unconditional positive regards among students. Without acceptance and respect, students are easy to put some judgements on others that can lead to the disapproval of individual differences and further cause some bullying behaviours. Nevertheless, it is understandable that students are struggling to accept and respect the differences among them, because they live in the diverse society with complex social segregation which might confuse them on how to behave or respond to individual differences. Moreover, family and relatives in collectivistic culture also take an important role in deciding who can be a friend for their children based on their values or beliefs. Therefore, every student has had their own idea about who can be their friends based on their judgement. Referring to the above responses, the perpetrators seem to bully students who are powerless such as having physical appearance and way to speak like a woman, physically weak, physically too small, and not smart enough.

According to Thornberg [51], the school bullying also strongly relates to complex power issues around maintaining face/image in front of adults such as teachers. It is quite rare that students can bravely bully their classmates in front of their teachers. Based on the results, $80 \%$ of students report that they experience bullying the most when school hours are empty or during lunch break. This also means that bullying usually happens when there was no teacher or adult present. The finding is in line with a study from Cadigan [57] that found school bullying typically occurs in the situation when the teachers are not present. Therefore, it is difficult to identify and prevent bullying in the school. Teachers with complex workloads are likely impossible to monitor or observe their students most of the time. Although they can indicate some signs of bullying within their lesson time, it is hard to know what is really happening to their students. Moreover, during the school time, students spend more time with their peer than with their teacher and even, they are really good at hiding their emotion. The victims who feel really distressed might look fine due to the threat from the perpetrators to not report them to their teacher [52]. Therefore, it is inevitable that the victims 
could experience severe distressed or trauma without any awareness from the school [1]. The lack of transparency from victims, perpetrators and witnesses lead to the minimum support that can be provided by the school to help the victims.

Although this study does not aim to find a strategy to deal with the school bullying, from the analysis and discussion of the findings, it can be suggested two further studies on how to deal with bullying and to prevent the victims suffering from severe post-traumatic stress. First, as the root issue of bullying is the lack of acceptance or unconditional positive regards and empathy and the context of bullying is usually within a peer group, it seems worthy to design action research about the effect of an experiential group exercise for both victims and perpetrators of bullying. The experiential group aims to facilitate the students to express their feeling around how and why it is difficult accepting individual differences. Second, based on Rogers' [59] a theory of personality, the individual's values or conditions of worth, play an essential part of how individuals judge something. Furthermore, people' judgments are greatly influenced by society and culture where they live. Therefore, it seems useful for further research to understand the social context of bullying, especially in Indonesia with full awareness of the cultural influence of school bullying. Further study is also required to investigate the level of PTS experienced by the students and its impact on the students' wellbeing to find the explanation on how severe the impacts of the school bullying towards the victims; therefore, the preventive programme can be developed.

\section{CONCLUSION}

The phenomena of school bullying among students in the study were understood as verbal, non-verbal or online actions that could trigger some physical risks, avoidance behaviours and difficult feelings towards the victims. The most common type of bullying was verbal bullying including taunting and name-calling accounting for $74 \%$ of the responses. The largest proportion of the most severe bullying was experienced by participants occurring in junior high schools. The results also showed that $40 \%$ of participants showed one or more symptoms of post-traumatic stress such as feeling persistently avoiding to the perpetrators and feeling extremely anxious about the potential being bullied again. The findings in the study were relevant and in line with the previous study that school bullying associates to the symptoms of post-traumatic stress. Besides, from the study, it can be suggested to the school counselors that they need to provide some anti-bullying programmes to support the students who experience school bullying to minimise the impacts of the school bullying, especially that are related to some symptoms of post-traumatic stress. In carrying out the programme of antibullying, school counselors are highly recommended to collaborate with other teachers, classmates, parents, community, and experts such as police, psychologist, and doctor. The collaboration enables the school counselor to observe the phenomena of school bullying that are often missed or hidden by the students. Eventually, it is important to develop further research considering the social contexts and cultural influence of school bullying. Further study is also suggested to investigate the level of post-traumatic stress experienced by the students and its impact on the students' wellbeing to find the explanation on how severe the impacts of the school bullying towards the victims to develop the preventive programme.

\section{REFERENCES}

[1] M. B. Nielsen, T. Tangen, T. Idsoe, S. B. Matthiesen, and N. Magerøy, "Post-traumatic stress disorder as a consequence of bullying at work and at school. A literature review and meta-analysis," Aggression and Violent Behavior, vol. 21, pp. 17-24, Mar. 2015, doi: 10.1016/j.avb.2015.01.001.

[2] F. C. Ossa, R. Pietrowsky, R. Bering, and M. Kaess, "Symptoms of posttraumatic stress disorder among targets of school bullying," Child and Adolescent Psychiatry and Mental Health, vol. 13, no. 1, p. 43, Dec. 2019, doi: 10.1186/s13034-019-0304-1.

[3] A. B. Klomek, F. Marrocco, M. Kleinman, I. S. Schonfeld, and M. S. Gould, "Peer victimization, depression, and suicidiality in adolescents," Suicide and Life-Threatening Behavior, vol. 38, no. 2, pp. 166-180, Apr. 2008, doi: 10.1521/suli.2008.38.2.166.

[4] Z. Nuryana, G. Al Murshidi, and A. Rahman, "Publication trends related to schizophrenia, mental health, and depression during COVID-19," Asian Journal of Psychiatry, vol. 66, Dec. 2021, doi: 10.1016/j.ajp.2021.102878.

[5] N. Kusumawardani, S. Rachmalina, Y. Wiryawan, A. Anwar, K. Handayani, and R. Mubasyiroh, "Health risk behavior in middle and high school students in Indonesia (In Indonesia: Perilaku berisiko kesehatan pada pelajar SMP dan SMA di Indonesia)." Jakarta: Badan Litbangkes Kementerian Kesehatan RI. 2015.

[6] M. E. Solberg and D. Olweus, "Prevalence estimation of school bullying with the Olweus Bully/Victim Questionnaire," Aggressive Behavior, vol. 29, no. 3, pp. 239-268, Jun. 2003, doi: 10.1002/ab.10047.

[7] L. Hackett, "The annual bullying survey 2019: the annual benchmark of bullying in the United Kingdom," 2019. https://www.ditchthelabel.org/wp-content/uploads/2019/11/The-Annual-Bullying-Survey-2019-1.pdf (accessed Oct. 18, 2021)

[8] N. Dian Paramita, "Disaster regime character: a study of disaster ris k reduction at merapi volcano eruption in Sleman dist rict," Journal of Government and Politics, vol. 3, no. 2, pp. 401-412, Aug. 2012, doi: 10.18196/jgp.2012.0023.

[9] S. S. Plexousakis, E. Kourkoutas, T. Giovazolias, K. Chatira, and D. Nikolopoulos, "School bullying and post-traumatic stress disorder symptoms: The role of parental bonding," Frontiers in Public Health, vol. 7, Apr. 2019, doi: 10.3389/fpubh.2019.00075.

[10] A. Nurlia and S. P. Suardiman, "The phenomenon of bullying in junior high school students nowadays," International Journal of Education and Learning, vol. 2, no. 1, pp. 7-13, Jun. 2020, doi: 10.31763/ijele.v2i1.62.

[11] D. Olweus, Bullying at School - What We Know and What We Can Do. Oxford: Blackwell Publishers, 1993. 
[12] S. Einarsen, "Harassment and bullying at work," Aggression and Violent Behavior, vol. 5, no. 4, pp. 379-401, Jul. 2000, doi: 10.1016/S1359-1789(98)00043-3

[13] N. Türkmen, H. Dokgöz, S. Akgöz, B. Eren, P. Vural, and O. Polat, "Bullying among high school students," Maedica A Journal of Clinical Medicine, vol. 8, no. 2, pp. 143-152, 2013.

[14] P. K. Smith, M. Singer, H. Hoel, and C. L. Cooper, "Victimization in the school and the workplace: Are there any links?," British Journal of Psychology, vol. 94, no. 2, pp. 175-188, May 2003, doi: 10.1348/000712603321661868.

[15] T. R. Nansel, M. D. Overpeck, D. L. Haynie, W. J. Ruan, and P. C. Scheidt, "Relationships between bullying and violence among US youth," Arch. Pediatr. Adolesc. Med., vol. 157, no. 4, p. 348, Apr. 2003, doi: 10.1001/archpedi.157.4.348.

[16] S. Joseph, "Client-centred therapy, post-traumatic stress disorder and post-traumatic growth: theoretical perspectives and practical implications," Psychology and Psychotherapy: Theory, Research and Practice, vol. 77, no. 1, pp. 101-119, Mar. 2004, doi: $10.1348 / 147608304322874281$.

[17] S. B. Matthiesen and S. Einarsen, "Psychiatric distress and symptoms of PTSD among victims of bullying at work," British Journal of Guidance \& Counselling, vol. 32, no. 3, pp. 335-356, Aug. 2004, doi: 10.1080/03069880410001723558.

[18] B. R. Walsht and E. Clarke, "Post-trauma symptoms in health workers following physical and verbal aggression," Work \& Stress, vol. 17, no. 2, pp. 170-181, Apr. 2003, doi: 10.1080/0267837031000148424.

[19] R. Lawrence, School crime and juvenile justice. New York: Oxford University Press, 1998.

[20] H. Mynard, S. Joseph, and J. Alexander, "Peer-victimisation and posttraumatic stress in adolescents," Personality and Individual Differences, vol. 29, no. 5, pp. 815-821, Nov. 2000, doi: 10.1016/S0191-8869(99)00234-2.

[21] K. S. McKenney, D. J. Pepler, W. M. Craig, and J. A. Connolly, "Psychosocial consequences of peer victimization in elementary and high school: An examination of posttraumatic stress disorder symptomatology," Child Victimization: Maltreatment, Bullying And Dating Violence, Prevention And Intervention, pp. 12-15, 2005.

[22] E. Andreou, S. Tsermentseli, O. Anastasiou, and E.-C. Kouklari, "Retrospective accounts of bullying victimization at school: associations with post-traumatic stress disorder symptoms and post-traumatic growth among University Students," Journal of Child \& Adolescent Trauma, vol. 14, no. 1, pp. 9-18, Mar. 2021, doi: 10.1007/s40653-020-00302-4.

[23] T. Idsoe, A. Dyregrov, and E. C. Idsoe, "Bullying and PTSD symptoms," Journal of Abnormal Child Psychology, vol. 40, no. 6, pp. 901-911, 2012, doi: 10.1007/s10802-012-9620-0.

[24] B. Houbre, C. Tarquinio, I. Thuillier, and E. Hergott, "Bullying among students and its consequences on health," European Journal of Psychology of Education, vol. 21, no. 2, pp. 183-208, Jun. 2006, doi: 10.1007/BF03173576.

[25] D. U. Patton, J. S. Hong, S. Patel, and M. J. Kral, "A systematic review of research strategies used in qualitative studies on school bullying and victimization," Trauma, Violence, \& Abuse, vol. 18, no. 1, pp. 3-16, Jan. 2017, doi: 10.1177/1524838015588502

[26] S. Perrin, R. Meiser-Stedman, and P. Smith, "The children's revised impact of event scale (CRIES): Validity as a screening instrument for PTSD," Behavioural and Cognitive Psychotherapy, vol. 33, no. 4, pp. 487-498, Oct. 2005, doi: $10.1017 / \mathrm{S} 1352465805002419$.

[27] M. Horowitz, N. Wilner, and W. Alvarez, "Impact of event scale: a measure of subjective stress," Psychosomatic Medicine, vol. 41, no. 3, pp. 209-218, May 1979, doi: 10.1097/00006842-197905000-00004.

[28] T. Nurhidayati, M. F. Mubin, and K. Al Faizin, "The description of bullying in high school students," Media Keperawatan Indonesia, vol. 2, no. 2, p. 31, Jun. 2019, doi: 10.26714/mki.2.2.2019.31-34.

[29] W. Chr. Argo, "Study of Javanese ethnic bullying victims from psychosocial perspective," Proceedings of the 1st International Conference on Education and Social Science Research (ICESRE 2018). Atlantis Press, 2019, doi: 10.2991/icesre-18.2019.23.

[30] OECD, PISA 2018 Results (Volume III) what school life means for students' lives. OECD, 2019.

[31] H. Nassaji, "Qualitative and descriptive research: Data type versus data analysis," Language Teaching Research, vol. 19, no. 2, pp. 129-132, Mar. 2015, doi: 10.1177/1362168815572747.

[32] A. Dardiri, F. Hanum, and S. Raharja, "The bullying behavior in vocational schools and its correlation with school stakeholders," International Journal of Instruction, vol. 13, no. 2, pp. 691-706, Apr. 2020, doi: 10.29333/iji.2020.13247a.

[33] E. G. Mikkelsen and S. Einarsen, "Basic assumptions and symptoms of post-traumatic stress among victims of bullying at work," European Journal of Work and Organizational Psychology, vol. 11, no. 1, pp. 87-111, Mar. 2002, doi: 10.1080/13594320143000861.

[34] D. L. Espelage and C. S. Asidao, "Conversations with middle school students about bullying and victimization," Journal of Emotional Abuse, vol. 2, no. 2-3, pp. 49-62, Mar. 2001, doi: 10.1300/J135v02n02_04.

[35] Silvy Dian Setiawan, "21 percent of school children in DIY still experience bullying," 2019. https://www.republika.co.id/berita/pmt27q383/21-persen-anak-sekolah-di-diy-masih-alami-perundungan (accessed Oct. 18, 2021).

[36] M. Seldin and C. Yanez, Student reports of bullying: Results from the 2017 school crime supplement to the National Crime Victimization Survey. Institute of Education Science, 2019.

[37] J. W. Santrock, Life-span development, 8th ed. New York: McGraw-Hill College, 2004.

[38] M. M. Ttofi, D. P. Farrington, and F. Lösel, "School bullying as a predictor of violence later in life: A systematic review and meta-analysis of prospective longitudinal studies," Aggression and Violent Behavior, vol. 17, no. 5, pp. 405-418, Sep. 2012, doi: 10.1016/j.avb.2012.05.002.

[39] A. P. Association, Diagnostic and statistical manual of mental disorders. American Psychiatric Association, 2013.

[40] Atle Dyregrov, Barn og traumer - en håndbok for foreldre og hjelpere av Atle Dyregrov, 2nd ed. Norway: Fagbokforlaget, 2010.

[41] F. de O. Pimentel, C. P. D. M. Cristina, and N. Dapieve Patias, "Vítimas de bullying, sintomas depressivos, ansiedade, estresse e ideação suicida em adolescentes," Acta Colombiana de Psicología, vol. 23, no. 2, pp. 205-240, Jul. 2020, doi: 10.14718/ACP.2020.23.2.9.

[42] C. Liu, Z. Liu, and G. Yuan, "The longitudinal influence of cyberbullying victimization on depression and posttraumatic stress symptoms: The mediation role of rumination," Archives of Psychiatric Nursing, vol. 34, no. 4, pp. 206-210, Aug. 2020, doi: 10.1016/j.apnu.2020.05.002

[43] J. Juvonen, A. Nishina, and S. Graham, "Peer harassment, psychological adjustment, and school functioning in early adolescence.," Journal of Educational Psychology, vol. 92, no. 2, pp. 349-359, Jun. 2000, doi: 10.1037/0022-0663.92.2.349.

[44] N. Tehrani, "Bullying: a source of chronic post traumatic stress?," British Journal of Guidance \& Counselling, vol. 32, no. 3, pp. 357-366, Aug. 2004, doi: 10.1080/03069880410001727567.

[45] B. A. Arnout, A. S. Alshehri, A. M. Assiri, and F. Y. Al-Qadimi, "Diagnostic criteria for postbullying disorder: A phenomenological research design of bullying victims," Journal of Public Affairs, vol. 20, no. 3, Aug. 2020, doi: 10.1002/pa.2063.

[46] L. Yasmin and E. Nurcahyani, "Post-traumatic stress disorder as bullying consequence: self-identity construction of a survivor in jennifer niven's holding up the universe," Journal International Seminar on Languages, Literature, Arts, and Education (ISLLAE), vol. 2, no. 1, pp. 79-87, Oct. 2020, doi: 10.21009/ISLLAE.02106. 
[47] L. Terr, "Childhood traumas: an outline and overview," American Journal of Psychiatry, vol. 148, no. 1, pp. 10-20, Jan. 1991, doi: 10.1176/ajp.148.1.10.

[48] R. Veenstra, S. Lindenberg, A. J. Oldehinkel, A. F. De Winter, F. C. Verhulst, and J. Ormel, "Bullying and victimization in elementary schools: A comparison of bullies, victims, bully/victims, and uninvolved preadolescents," Developmental Psychology, vol. 41, no. 4, pp. 672-682, 2005, doi: 10.1037/0012-1649.41.4.672.

[49] J. A. Horowitz et al., "Teasing and bullying experiences of middle school students," Journal of the American Psychiatric Nurses Association, vol. 10, no. 4, pp. 165-172, Aug. 2004, doi: 10.1177/1078390304267862.

[50] P. Hamarus and P. Kaikkonen, "School bullying as a creator of pupil peer pressure," Educational Research, vol. 50, no. 4, pp. 333-345, Dec. 2008, doi: 10.1080/00131880802499779.

[51] R. Thornberg, "Schoolchildren's social representations on bullying causes," Psychology in the Schools, vol. 47, no. 4, pp. 311327, Apr. 2010, doi: 10.1002/pits.20472.

[52] R. Thornberg and S. Knutsen, "Teenagers' explanations of bullying," Child \& Youth Care Forum, vol. 40, no. 3, pp. 177-192, Jun. 2011, doi: 10.1007/s10566-010-9129-z.

[53] R. Thornberg, "'She's weird!'- the social construction of bullying in school: A review of qualitative research," Children \& Society, vol. 25, no. 4, pp. 258-267, Jul. 2011, doi: 10.1111/j.1099-0860.2011.00374.x.

[54] R. Kennedy and A. K. Widjojoatmodjo, "Acculturation and administration in Indonesia," American Anthropologist, vol. 45, no. 2, pp. 185-192, Apr. 1943, doi: 10.1525/aa.1943.45.2.02a00020.

[55] G. Hofstede, "The business of international business is culture," International Business Review, vol. 3, no. 1, pp. 1-14, Mar. 1994, doi: 10.1016/0969-5931(94)90011-6.

[56] N. Sutanti, "Exploring the challenges of the non-directive attitude in person-centred counselling in Indonesian culture," KnE Social Sciences, Jun. 2019, doi: 10.18502/kss.v3i17.4621.

[57] R. J. Cadigan, "Scrubs: An ethnographic study of peer culture and harassment among sixth graders in an urban middle school," University of California, Los Angeles, 2002.

[58] C. Phillips, "Who's who in the pecking order?: aggression and 'normal violence' in the lives of girls and boys," British Journal of Criminology, vol. 43, no. 4, pp. 710-728, Oct. 2003, doi: 10.1093/bjc/43.4.710.

[59] C. Rogers, A theory of therapy, personality, and interpersonal relationship as developed in the client-centred framework, "in Psychology: a study of a science, study I. Conceptual and systematic: Vol. 3 formulations of the person and the social context. London: McGraw-Hill, 1959.

[60] C. R. Rogers, On Becoming a Person: A Therapist's View of Psychotherapy - Carl Ransom Rogers - Google Buku. New York: Houghton Mifflin Harcourt, 1961.

\section{BIOGRAPHIES OF AUTHORS}
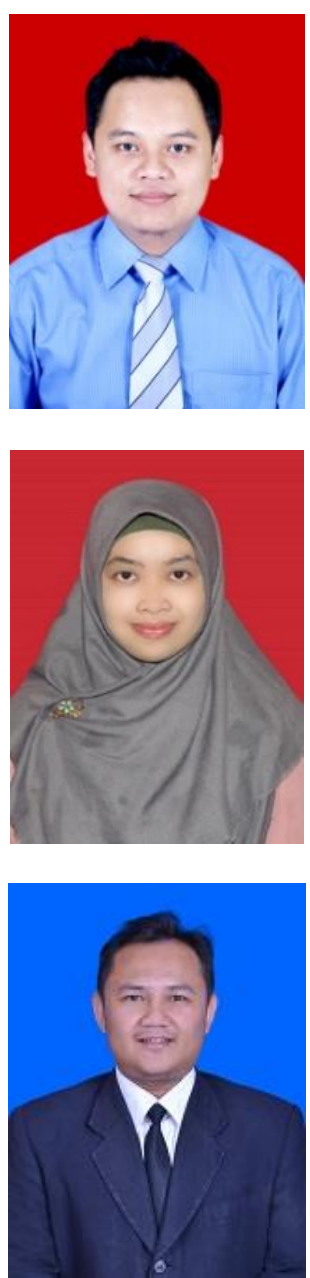

Luky Kurniawan (D) SC P is an assistant professor at Department of Guidance and Counseling, Universitas of Mercu Buana Yogyakarta, Indonesia. His current research interests include academic guidance and counseling, guidance and counseling management, social and emotional learning (SEL). He can be contacted at email: luky@mercubuana-yogya.ac.id

Natri Sutanti (D) 8. SC P is a lecturer at Department of Guidance and Counseling, Universitas Mercu Buana Yogyakarta. She is graduated from Master of Person-centred Experiential Counselling and Psychotherapy Practice. Her research interests are art therapy, prosocial behaviour, trauma dan therapeutic relationship. She can be contacted at email: natrisutanti93@gmail.com.

Zalik Nuryana (D) $8 \mathrm{SC}$ P is an assistant professor at Universitas Ahmad Dahlan Indonesia, Islamic Education department. He is currently a Ph.D. student in School of Education Science, Nanjing Normal University China. His areas of interest include curriculum development, teaching method, and online learning. $\mathrm{He}$ can be contacted at email: zalik.nuryana@pai.uad.ac.id; zalik@ascee.org; zalik@ieee.org. 